\title{
Proyectos y controversias editoriales de Schopenhauer Selección epistolar
}

Las cartas que se presentan a continuación muestran dos facetas poco conocidas de la vida y el trabajo intelectual de Schopenhauer: sus dotes e inclinaciones como traductor, así como su agudo sentido editorial. Se trata de correspondencia que habría mantenido con editores y que gozan lo mismo de lo anecdótico que de la reflexión filosófica en torno a obras filosóficas y literarias. Estas cartas serán publicadas en el volumen Correspondencia de Arthur Schopenhauer en 2008 por la casa editorial «Los libros de Homero», a la cual los editores de esta publicación agradecen la gentil cesión. La traducción estuvo a cargo de Eduardo Charpenel - quien actualmente traduce la reciente y completa biografía de Jünger del profesor Kiesel de la Universidad de Heidelberg, publicada en Siedler-.

\section{[A un editor] \\ Distinguido Señor:}

Me tomo la libertad de hacerle una propuesta. Debido al triste estado actual de la filosofía en Alemania considero que la traducción de dos escritos de Hume sería muy conveniente.

Los escritos en cuestión son los siguientes. En primer lugar, se trata de la Historia natural de la religión. Este pequeño escrito, el cual considero que es el más importante de los dos, apareció sólo una vez en Inglaterra después del año de 1755. Se tradujo al alemán en 1759 y se publicó con tres pequeños apartados de Hume de contenidos completamente heterogéneos. Esta traducción no sólo está pésimamente escrita, sino que también está pasada de moda y es a menudo imprecisa. 
En segundo lugar, sus Diálogos sobre la religión natural. Éstos fueron traducidos en el año 1781 y publicados junto al apartado de Plattner sobre el ateísmo. No he llegado a ver esta traducción; probablemente se encuentra agotada desde 1781.

De acuerdo a sus contenidos, estos escritos forman un conjunto, a pesar de que el último apareció únicamente después de la muerte de Hume, ya que le temía al celo religioso de sus compatriotas. Sería, pues, muy conveniente reunirlos mediante una nueva traducción que podría ser presentada bajo el título La filosofía de la religión de Hume. La extensión sería aproximadamente de doscientas cincuenta páginas. La tendencia de ambos escritos es la de mostrar, en primer lugar, que la creencia en los dioses, sean éstos muchos o uno, y la adoración que se les rinde, tienen como origen la angustia y el miedo ante las fuerzas violentas y desconocidas, lo cual provoca que el género humano viva en un estado prácticamente vegetativo entre sufrimientos diversos y conocimientos nulos. En segundo lugar, pretenden mostrar la completa insuficiencia de todas las pruebas de la existencia de Dios. La realización de esto en su conjunto es magistral, aguda y atinada, y su lenguaje no sólo es comprensible sino profundamente atractivo, lleno de humor e ingenio en cada una de sus páginas. Precisamente, debido a su objeto de estudio y a su estilo, pienso que esta traducción puede volverse con facilidad parte de la filosofía popular, y que no será recibida fríamente, como sucede por lo común con la filosofía en la actualidad. Encontrará un amplio público de lectores, y éste se ensanchará conforme crezca la oposición contra estos escritos. Podría colocarse fácilmente en una posición semejante al escrito de Benjamin Constant traducido al alemán: La religión.

En lo que respecta a mi talento como traductor: aprendí el inglés durante una estancia en Londres en mi juventud con un catequista, y mantengo todavía dichos conocimientos frescos. $\mathrm{Mi}$ conocimiento es tal que los ingleses - con quienes, por cierto, recientemente volví a convivir en un viaje a Italia - confiesan no haber oído nunca que un extranjero hablase su idioma de modo tan perfecto. En dos ocasiones incluso llegaron a pensar por un rato que yo mismo era inglés. Mi buen alemán puede comprobarlo usted a través de mis escritos. Incluso quienes se oponen a mis pun- 
tos de vista no han dejado de señalar la gran fuerza y vivacidad de mi estilo. Por eso me siento muy confiado de hacer una traducción del inglés muy bien acabada y completamente distinta de aquel trabajo de fábrica que se realiza con la ayuda de un diccionario. Comúnmente, las traducciones buscan conservar el sentido, pero no hacen ningún esfuerzo por transmitir el espíritu del original.

Le ofrezco mis servicios como traductor de prosa inglesa no sólo de la filosofía, sino también de todas las ciencias naturales, historia, política, e incluso novelas. Puedo asegurarle que en cualquier caso sus expectativas quedarían satisfechas, ya que pocos están tan capacitados para este trabajo como yo.

Asimismo, le ofrezco mis servicios como traductor del italiano. Tanto por mi estancia en Italia por dos años, como por diversas lecturas, estoy familiarizado con este idioma. Hay un importante trabajo en italiano de Giordano Bruno, Della causa, principio e uno ${ }^{1}$, que recientemente se ha vuelto célebre debido a Schelling y a Jacobi. El autor de este libro fue quemado en 1600, y su libro, donde fuera que éste se encontrara, fue quemado también. Un ejemplar se conserva aquí y otro se encuentra en München en la biblioteca que Jacobi dejó en su legado. Se trata de un diálogo y no creo que tenga una extensión mayor a doce octavos. Sería conveniente hacer accesible este libro a todos los lectores instruidos mediante una edición bilingüe en latín. El original está en italiano, pero yo con gusto haría la versión latina.

Espero su respuesta para poner manos a la obra.

Muy sinceramente

Arthur Schopenhauer. Dresden, 25 de mayo de 1824.

\section{[A F. A. Brockhaus]}

Desde que tuve el honor en septiembre de irlo a visitar a Leipzig, me ofrecí a realizar para usted algunas traducciones del inglés y del italiano. En vista de que usted elabora una colección de nove-

1 «De la causa, principio y uno». 
las clásicas extranjeras, sería para mí un enorme placer traducir el inmortal Tristram Shandy de Sterne. Es uno de los libros que constantemente vuelvo a leer. Hay una traducción alemana, creo que de Bode, que supuestamente es buena pero que no conozco. $\mathrm{Su}$ idioma, sin embargo, no es el de hoy y actualmente se necesita de algo mejor. En todo caso, yo haría con amore dicha traducción con el propósito de recrear enteramente la impresión vivaz del exquisito original. Como conozco el inglés desde mi juventud en Inglaterra y lo domino tanto como el alemán, creo poder llevar a cabo un excelente trabajo. Dejo esto a su amable consideración.

Su muy devoto,

Arthur Schopenhauer. Dresden, 26 de enero de 1825.

\section{[A F. A. Brockhaus]}

Señor mío

Me tomo la libertad de mandarle un manuscrito para su revisión; creo que podría convertirse en un gran artículo editorial. Sin embargo, por motivos muy personales no quiero que se me reconozca como el traductor del mismo, por lo que le pido que guarde la máxima discreción al respecto, ya sea que lo acepte o no. Me dispongo ahora a darle todos los datos literarios que hacen de este libro algo todavía au fait ${ }^{2}$.

El Oráculo manual y arte de prudencia del jesuita Baltasar Gracián apareció en España en 1653 y poco después fue traducido al francés bajo el famoso título L'homme de tour de Gracian; traduit par Amelot de la Houssaye: esta traducción está bastante incompleta, y quien la hizo sólo entendió el texto a medias. Sin embargo, muy pronto aparecieron dos traducciones al alemán basadas en el texto francés, una de Sauer en 1685 (Leipzig), y otra de Salintes en 1711 (Augsburg). Ambas traducciones son miserables, pues estos dos no sabían nada de francés y, como ya le he dicho, la misma traducción francesa está llena de errores. Sin embargo, la obra vol- 
vió a traducirse en 1750, esta vez del francés al latín, bajo el título Gratiani homo aulicus y apareció en Viena. Esta traducción es difícil, complicada, y en algunas partes completamente incomprensible. Asimismo, en 1715 apareció en Leipzig una traducción de A. F. Müller realizada directamente del español. En muchas partes, aunque no siempre, esta versión no capturó varias cosas del original, y es más una paráfrasis que una verdadera traducción. De ahí que sea tres o cuatro veces más extensa que el original, y que no se encuentre en ella ninguna huella del espíritu y el tono del mismo; en vez de aquella riqueza de pensamientos expresada con pocas palabras - una de las características más distintivas del original, encontramos aquí líneas rimbombantes e insípidas, escritas en aquel estilo tan repugnante de la época (1715) que hoy nos resulta completamente ilegible. Además, Müller añadió sus comentarios moralinos de una manera tan adusta y amplia que convirtió la obra de Gracián en un mamotreto de más de 1790 páginas impreso en tres tomos. Ésta ha sido la última traducción alemana de este famoso libro. Hay también una traducción italiana anterior que no he podido conseguir. Las obras completas de Gracián aparecieron en dos tomos en 1702 en Amberes. Mi traducción se basa en esta edición. La necesidad contemporánea de traducir a Gracián al alemán se manifestó - aunque, de ningún modo se cubrió de manera satisfactoria - en un panfleto publicado en Leipzig en 1826 titulado El cuadernillo negro: ideas de Gracián sobre la sabiduría práctica, de ochenta páginas, cuyo precio era de seis centavos.

Este desafortunado producto mercantil parece haber sido escrito por algún criado. De ninguna manera se trata de una traducción del español. Quien lo redactó empleó la traducción francesa, y en ocasiones, de las 300 máximas de Gracián, tomó aquello que le parecía, unió las cosas más heterogéneas y les agregó frases de su propia cosecha. Con esta mezcolanza definitivamente afectó la cohesión del original, y aparte de todo le añadió cincuenta apartados de su propia composición, formando así un volumen cuya extensión es la de un cuarto respecto al original. En ningún lugar podemos encontrar recogidos los pensamientos de Gracián de manera pura; tampoco hay huella alguna de aquel noble y elevado tono con el que habla. En lugar de eso, encontramos un discurso 
que no es sólo corriente sino también pésimo. Duele ver a un escritor tan grande en un estado tan maltrecho y desfigurado. Le adjunto mi ejemplar de esa mamarrachada para que la compare con mi traducción y compruebe lo que digo: en él añadí los números de las que son las primeras cincuenta máximas y que él desperdigó por doquier.

De las 300 máximas para la vida de Gracián, traduje las primeras cincuenta tal y como aparecen en el original, de manera literal y tan fiel como era posible, haciendo fácil su comprensión: el señor Keil, o quien sea que hable español, le confirmarán esto si comparan mi traducción con el original, y le dirán también que realicé el mejor trabajo posible, pues no sólo preservé el sentido exacto, sino también el tono y el sentido, y además redondeé el texto y lo hice más fluido al limar ciertas asperezas y al mejorarlo en algunas cosas. Estoy plenamente convencido que cualquier lector atento, aunque se trate de una mujerzuela, podría entenderlo. Hacer esto es mucho más difícil de lo que parece, ya que, a su propio modo, se trata de una pequeña obra maestra.

Este libro puede aparecer de nueva cuenta, con la acreditación y el aplauso de más de un siglo y medio, pero ahora tal y como apareció en España, con su verdadera y auténtica forma, ya que todas las traducciones anteriores son, de alguna forma $\mathrm{u}$ otra, raquíticas. Este libro es un manual de artes práctico, apropiado tanto para consejeros como para granjeros, y, de manera particular, para aquellos que son jóvenes y buscan abrirse paso por el mundo. De ahí que todos aquellos que le echen un vistazo quieran no sólo leerlo sino también poseerlo, pues no se trata de una lectura ocasional, sino de un libro que sirve como tutor y como guía.

Traduje sólo estas máximas - que apenas conforman una sexta parte del original- porque aquellas que aparecen más adelante son mucho más extensas. Calculo que toda la traducción quedaría recogida en 10 pliegos, junto con un prólogo y una nota editorial. De aceptar el libro, usted tendría que imprimir 1000 elegantes ejemplares de 24 páginas cada uno. Aproximadamente, 150 ejemplares estarían destinados para un público refinado - mismo al que la obra ensalza - y tendrían que ser impresos en vitela. Por concepto de honorarios, le pediría a usted 120 ducados, en el entendido de 
que si hubiera una siguiente edición, yo percibiría de nuevo esta misma suma. Si usted no aceptase esta última condición, y quisiera pagarme por una segunda edición sólo la mitad, entonces tendría que pagarme por esta primera edición 170 ducados.

De ningún modo pienso ceder en esta última condición, pues se corresponde a mi trabajo y es la recompensa justa al mismo.

Por algún motivo u otro, si usted no desease aceptar este contrato, pero quisiera que otro editor se encargara del mismo, yo no tendría problemas con ello: sólo que éste no podría saber mi nombre hasta que el asunto haya sido arreglado. Si nadie lo quisiera aceptar, le pediría que me regresara el manuscrito así como el libro para que yo buscara aquí a un editor.

Con la plena confianza de que usted no habrá de revelar mi nombre a nadie, queda de usted

Su atento servidor

Arthur Schopenhauer. Berlin, 15 de mayo de 1829.

\section{[A Carl Rosenkranz y Friedrich Schubert]}

A los profesores Rosenkranz y Schubert

Universidad de Königsberg

¡Honorables señores!

Sólo en virtud de su calidad de editores de las obras completas de Kant me tomo la libertad de comunicarles ciertos propósitos que he albergado durante años, y que daría a conocer a todo aquel que tuviese una empresa en sus manos semejante a la de ustedes. Si bien esto no lo hago en beneficio mío o suyo, sino motivado por el más puro y objetivo interés por la filosofía kantiana, creo que lo que les comunicaré les será provechoso, pues así podrán cumplir honorablemente con la obligación que asumieron y serán alabados por hacer aquello que les correspondía como editores. Pues, a excepción de un único aspecto que habré de comentarles, no hay nada que mejorar. No es difícil presentar estas obras íntegramente y bien impresas, y el orden de los libros es a final de cuentas arbitrario. 
En lo que a mí concierne, puedo suponer que conocen mi relación con la filosofía kantiana así como mi crítica a la misma. Desde hace 27 años la filosofía de Kant no ha dejado de ser el tema principal de mis estudios y de mis reflexiones. ¡Me gustaría saber quién de mis contemporáneos es más competente que yo en lo que concierne a la filosofía kantiana! Pero bueno, vayamos al asunto.

Como es sabido, Kant le hizo importantes modificaciones a la Crítica de la razón pura en su segunda edición: y es a partir de esta segunda edición que se han impreso todas las siguientes reimpresiones. Sin embargo, mis detallados estudios me han brindado la segura y firme convicción de que Kant mutiló, desfiguró y echó a perder su obra mediante dichas modificaciones. Lo que lo motivó a hacer esto fue el temor a los hombres provocado por su vejez, un temor que ataca no sólo a la cabeza, sino que también se apodera con firmeza del corazón, y que hace a uno odiar a todos sus contemporáneos después de haberles brindado un servicio - muchos grandes hombres han hecho esto- . A Kant le echaron en cara que su doctrina era un refrito del idealismo de Berkeley; pues como había derribado con su doctrina las viejas y sagradas enseñanzas de los dogmáticos - en especial, las de los psicólogos racionalistas - eso hizo enfurecer a varios. Además, falleció el gran rey, aquel amigo de la luz y protector de la verdad, y Kant tuvo que prometerle a su sucesor que no volvería a escribir más. Kant fue intimidado por estas circunstancias, y al final acabó por flaquear y realizó cosas indignas de su persona. Entre las cosas que hizo, modificó el primer apartado del segundo libro de la dialéctica trascendental (página 341 de la primera edición, y 339 de la quinta), y eliminó 32 páginas del mismo que son en realidad indispensables para la correcta comprensión de toda la obra. Al sustraer esto y al incorporar otros apartados, llenó toda su doctrina de contradicciones, mismas que señalé y ataqué en mi crítica a Kant, pues en ese entonces (1818) no había visto la primera edición donde no hay contradicciones y todo es armonioso. A decir verdad, la segunda edición se parece a un hombre al que le han amputado una pierna y le han colocado en su lugar una de madera. En la página XLII del prefacio a la segunda edición justifica la eliminación de la parte más bella e importante del libro con peladas y falsas 
excusas; ahí su intención no es la de confesarse y retractarse por aquello que eliminó: según Kant, uno puede ver que en la primera edición es necesario dar mayores explicaciones, y que aquello que insertó no es más que una exposición mejorada. Sin embargo, la falsedad de este pretexto resulta evidente cuando uno compara la segunda edición con la primera. Pues en la segunda edición no sólo eliminó aquel hermoso e importante apartado que he mencionado e insertó otro nimio y de mucha menor extensión, sino que en la segunda edición (páginas 274-279 de la quinta edición, no sé si las páginas se correspondan con la segunda edición que ustedes poseen) incorpora una abierta refutación al idealismo que expresa justo lo contrario a lo que la anterior decía, y todos los errores que anteriormente había criticado con solidez los comete él mismo. Como consecuencia de esto, Kant dejó toda su doctrina llena de contradicciones. La supuesta refutación del idealismo que insertó es tan mala, se encuentra llena de tantos sofismas evidentes, $y$ abunda en tantos galimatías confusos, que no es digna de estar en esta obra inmortal. Con plena conciencia de estas deficiencias, Kant defendió dicha eliminación en la página XXXIX del prólogo con señalamientos confusos, arguyendo que buscaba mejorar la exposición. Pero el anciano olvidó tachar sin excepción todos los pasajes de la segunda edición que contradecían lo que añadió, y que armonizaban a la perfección con lo que había quitado. Estos pasajes son, a saber, toda la sección sexta de las antinomias de la razón pura, así como los otros lugares que señalé con desconcierto en mi crítica de 1818, pues desconocía la primera edición - espero, por cierto, que con esto no tengan dudas de que los aconsejo no a favor, sino incluso en contra de mi propio interés personal-. Por otra parte, se puede apreciar que fue el temor a los hombres lo que llevó a este anciano a desfigurar su crítica contra la psicología racionalista, ya que sus ataques contra aquella sagrada doctrina del viejo dogmatismo son mucho más taimados, débiles y sin fundamento en la segunda edición que en la primera; este temor a los hombres resulta también evidente si uno considera las dilucidaciones que insertó sobre la inmortalidad del alma como un postulado necesario para la razón práctica, que nada tienen que ver con la estructura y el contenido de la obra y que además son franca- 
mente incomprensibles. Este miedoso retroceso provocó también que Kant se deslindara del punto más importante de toda su filosofía, a saber, la relación entre lo real y lo ideal, un pensamiento que albergó durante sus años de mayor vigor, y que con 64 años a cuestas rechazó con ligereza - la cual, en la vejez, se confunde con el miedo-; sin embargo, por vergüenza, no hizo esto públicamente, sino que lo hizo a hurtadillas y dejó abandonado a su sistema. De ahí que la Crítica de la razón pura sea en su segunda edición una obra contradictoria, mutilada y echada a perder: ciertamente, es falsa. Jacobi concuerda plenamente conmigo en este punto, pues en la segunda parte de sus obras completas reproduce una sección de aquello que Kant suprimió.

Señores míos, el destino ha puesto en sus manos la oportunidad de reproducir la Crítica de la razón pura, el libro más importante que en la historia ha sido escrito en Europa, de manera original, inalterada y en su auténtica forma; mediante esta restitutio in integrum ${ }^{3}$, podrán ganarse el aplauso de todos, conseguir el agradecimiento de la posteridad, y realizar la empresa que tienen ante sí con honor.

Esto ocurriría justo al tiempo que comienza la vida de este libro escrito para todos los tiempos, pues Francia e Inglaterra ya exigen con avidez esta fuente de sabiduría. No dejen esta necesaria tarea a otra época y no oscurezcan su labor como editores: sean conscientes de la importancia de su posición y aprovechen la oportunidad de otorgarle un auténtico y duradero servicio a la filosofía, tomen el aliento necesario para dar este paso, cuya osadía - justificada plenamente por la naturaleza del asunto- seguramente los revestirá de honor. Sapere aude! Impriman la Crítica de la razón pura de acuerdo a la primera edición y añadan los complementos y las variantes de la segunda edición como un suplemento. Así se respetará el orden cronológico: ustedes presentarían la obra en su verdadera forma, tal y como Kant se la brindó al mundo tras

3 «Restitución al estado original».

4 «Atrévete a conocer» famosa frase latina de Horacio (Epístolas, I, 240) retomada por Kant como lema de la Ilustración. Kant la traduce en su famoso ensayo «¿Qué es la Ilustración?« como «iten el valor de servirte de tu propia razón!». 
muchos años de esfuerzo, y después añadirían las modificaciones que hizo a su trabajo.

He cotejado minuciosamente ambas ediciones y he anotado todas las divergencias y modificaciones; me ofrezco a enviarles un registro confiable de todas las diferencias hecho página por página y línea por línea. Ustedes sólo tendrían que revisarlo y se ahorrarían cualquier otro esfuerzo. La primera edición tiene tan sólo 27 páginas menos que las otras: la unidad original de la obra se vuelve mucho más clara en su forma y constitución originales, y en muchos lugares concretos es mucho más comprensible que en la segunda edición. Esto se ve incluso en la tabla de contenidos: la primera es mucho más clara que la segunda.

No se dejen superar por otros emprendedores, no se queden atrás en el amplio pabellón de los señores - algo que Pitágoras ya había advertido - , y no dejen las cosas a medias. Presenten la primera edición y añadan aparte las variantes de la segunda. No hacerlo sería como si uno descubriese una antigua escultura y en vez de pegarle las partes faltantes uno las dejara tiradas a un lado. Aprovechen esta brillante oportunidad para dar una prueba de su conocimiento y de su juicio, y actúen como lo exige la naturaleza del asunto. Seguir li pochi e non la volgar gente ${ }^{5}$. Si ustedes así lo deciden, no tendría inconveniente alguno en que me nombraran consejero editorial de la obra. Estoy tan convencido de la pertinencia de estos consejos que estoy dispuesto a asumir plena responsabilidad por los mismos. Si ustedes quisieran excusar su procedimiento, podrían justificarse publicando la presente carta, desde la parte donde digo «como es sabido» hasta donde escribo «ciertamente, es falsa», pero tendrían que nombrarme explícitamente y tendrían que publicar la carta sin modificaciones de ningún tipo. Muchos comprarían su edición con el fin de ser dueños de la Crítica de la razón pura en su forma original, y de la que sólo han oído por la tradición, a diferencia de esa mutilada segunda edición, que es muy popular y ya lleva seis o siete ediciones. Éste sería el argumento para el editor general. Está por demás decirles que por este

5 «Sigan a los pocos y no a la muchedumbre». 
servicio no espero ni exijo la más mínima retribución. Si aceptan seguir mi consejo, lo único que les pediría es que publicaran una pequeña nota donde mencionaran mi nombre y lo que he sugerido. Tampoco les ocultaré el hecho de que si ustedes no toman mi consejo, yo me esforzaré por mi parte en presentar la Crítica de la razón pura en su forma original: algo que seguramente afectaría la edición de ustedes. A mí lo único que me importa es que esto se maneje como es debido sin importar quién sea quien lo haga. Dixi et animam salvavi ${ }^{6}$.

Con mis deseos más sinceros para el desarrollo afortunado de su honorable empresa, quedo de ustedes como

Su más sincero servidor

Arthur Schopenhauer. Frankfurt, 24 de agosto de 1837.

\section{[A Carl Rosenkranz] \\ ¡Honorable señor!}

Reciba usted mi más sincero agradecimiento por el bello ejemplar de su edición de la obra de Kant, cuyos tomos I y IX - bellamente encuadernados - me han llegado en el invierno. El diseño es bastante adecuado, y lo que usted ha hecho en cuanto a la ordenación de los libros, y las correcciones ortográficas y de puntuación es realmente admirable. Aguardo con expectación la próxima edición de la Crítica de la razón pura, y así contemplarla como si hubiese vuelto a nacer.

Por otra parte, creo que en su prefacio al primer tomo debió haber mencionado que en La única prueba posible de la existencia de Dios (1763), Kant expone por segunda vez y de manera completa sus hipótesis cosmológicas, aquellos pensamientos tan infinitamente perspicaces y verdaderos que por sí mismos habrían bastado para hacer inmortal su nombre. La primera vez que los expuso fue en su Historia universal de la naturaleza y teoría del cielo de 1755: aquel escrito tan poco leído entre la raza de monos que anda en dos pa- 
tas. Tiempo después, Lambert robó ( $u$ t fere fit ${ }^{7}$ ) esos pensamientos en 1761 (como Kant mismo da a entender, en el señalamiento que se encuentra en la pág. 167, de su edición). Kant repite esta exposición - de manera perfectamente acabada - en el ya mencionado escrito, en la séptima consideración (págs. 254-271); irónicamente, lo coloca junto a la demostración de la existencia de Dios, un lugar donde su teoría figura de manera tan curiosa que parece ser más bien una refutación contra la omnisuficiencia divina. La apatía generalizada, la atracción por todo lo malo y la repulsión por todo lo bueno tan difundidas en Alemania hacen que la gente no se ocupe de Kant ni de Lambert ni de la cosmogonía. Es por ello que ahora, 50 años después, un francés llamado Laplace pretende haber descubierto estas ideas por sí mismo y busca revestirse con ellas de gloria: bajo el nombre de Cosmogonía de Laplace las ideas descubiertas por Kant hace 50 años (algo completamente cierto y demostrable) son ahora famosas. Laplace da cuenta de ellas en su Exposition du système du monde, libro V, capítulo 6, iy dice (en la p. 430 de la cuarta edición) que no conoce a nadie antes de él que haya intentado explicar el surgimiento de los cuerpos celestes, salvo Buffon, quien lo hizo de manera completamente distinta! ¡Y toda su cosmología no es más que una repetición de la kantiana! Pienso que podría reivindicar el mérito de Kant por estos bellos y verdaderos pensamientos en el prólogo a la Historia universal de la naturaleza y teoría del cielo; con esto usted también reivindicaría a la nación alemana, pero eso no es algo que me importe.

Albergo desde hace tiempo un deseo que quizás usted pueda cumplirme: un autógrafo de Kant. Lo único que poseo de él es una mera reproducción de su firma en grandes letras doradas que se encuentra debajo de un grabado que poseo. Un misterioso juez Fischenich de Berlín me envió una nota supuestamente escrita por Kant, pero como después de examinarla no encontré ninguna evidencia que diera cuenta de su legitimidad, le regresé aquel papel sin valor, mientras que él se quedó sin más una carta autógrafa de Goethe que yo le había enviado. Esta persona ya murió; espero

7 «Como suele hacerse». 
que se comporte de mejor manera en la otra vida. Si usted posee un autógrafo original o algo de esta naturaleza y quisiera otorgármelo, quedaría agradecido para siempre

$\mathrm{Su}$ fiel servidor

Arthur Schopenhauer. Frankfurt, 12 de julio de 1838.

[A F. A. Brockhaus]

A mi señor

Le parecerá perfectamente normal que me dirija a usted para encargarle la edición del segundo tomo de El mundo como voluntad y representación, que apenas ahora he completado. Lo que quizás le sorprenda, por otra parte, es que lo haya terminado 24 años después de haber escrito el primero. A pesar de que me he ocupado con los preparativos de manera incesante no lo pude haber completado antes. Lo que ha de permanecer por mucho tiempo se gesta con lentitud. La redacción final de este tomo ha sido mi trabajo por los últimos cuatro años: tomé esta decisión porque me di cuenta de que era tiempo de acabar. He alcanzado la edad de 55 años, un etapa en que la vida se empieza a volver más incierta - eso si es que uno sigue vivo-, y las fuerzas del espíritu comienzan a debilitarse.

Este segundo tomo contiene ventajas importantes en relación al primero; la relación que guardan entre ambos es la misma que hay entre un cuadro pintado y su bosquejo. Este tomo aventaja al primero en solidez de pensamientos y de conocimientos, los cuales son el fruto de una vida entera dedicada al estudio y la reflexión. Ciertamente, es lo mejor que he escrito, pero justo ahora es que se podrá apreciar la importancia del primer tomo. Me he expresado en esta ocasión con mucha mayor libertad y franqueza que hace 24 años; en parte, esto se debe a que el tiempo me ha dado mayor madurez, y en parte, también, a que con el paso de los años he conseguido librarme definitivamente de los ridículos universitarios y he asegurado mi independencia.

Según mis cálculos, la extensión de este tomo debe ser semejante a la del primero, pero esto no se lo puedo asegurar con pre- 
cisión, ya que he utilizado distintas columnas y márgenes en la composición del manuscrito. Éste se divide en 50 capítulos que a su vez se dividen en cuatro libros que corresponden a los cuatro libros del primer tomo.

Mi más ardiente deseo es que usted decida imprimir este tomo así como el primero y que ambos aparezcan en una «segunda edición aumentada, en dos tomos», de modo que esta obra - cuyo valor e importancia apenas comienza ha ser reconocido por algunas personas-, sea presentada en una forma más apropiada y actual, y logre así atraer la atención del público. Esperemos que esta obra desenmascare las fantasmagorías que han predicado por tanto tiempo nuestros aclamados y heroicos catedráticos, y que su vacuidad sea reconocida; por otra parte, el deterioro de la religión en nuestro tiempo ha despertado el interés por la filosofía: hoy en día se siente más fuerte que nunca esta necesidad y no hay filosofía alguna que la cubra. Las obras de los demás tienen como objetivo el interés propio - algo que no es en absoluto mi caso - y ninguna otra cosa más. Ahora que la he completado ha llegado el momento de que aparezca mi obra con una nueva y perfecta forma. La gente no será por siempre injusta conmigo. Si usted conoce la historia de la literatura, sabrá que todas las obras auténticas que gozan de una longevidad considerable fueron en un principio desatendidas mientras que las pésimas y las falsas se hallaban en lo alto. Pareciera como si las cosas buenas y auténticas ya no tuvieran lugar en este mundo y no merecieran alcanzar la gloria; sólo atravesando diversos escollos llegan éstas a la luz. Mi tiempo habrá de llegar, y entre más tarde llegue más luminoso será. Ésta es una obra cuyo valor e importancia es de tal naturaleza que ni siquiera aquí entre bastidores con mi editor me atrevo a pronunciarla pues de hacerlo no me creería. Lo que puedo hacer es al menos señalarle lo importante que es este asunto para mí y hacerle saber que no guardo ningún propósito ulterior. Si usted decide hacerse cargo de la segunda edición, dejaré a su buen criterio si es que he de percibir dinero por ambos tomos, o ninguno en lo absoluto. En este último caso, usted obtendría el trabajo de toda mi vida gratis, aunque he de decirle que no lo llevé a cabo con una disciplina de hierro hasta mi vejez buscando obtener dinero a 
cambio. Por otra parte, sé de sobra que un libro de este volumen implica para usted un costo considerable en impresión y papel, y que sólo habrá de recuperar la inversión con el tiempo. Tengo muy presentes sus quejas sobre las bajas ventas y sus informes sobre la destrucción de varios libros: ambas cosas me han provocado una enorme tristeza. Sin embargo, sé que esto no se debe al libro en sí, sino a la nula capacidad de juzgar del público, y a la socarronería de los profesores de filosofía más influyentes que actúan de acuerdo a sus propios intereses. Mientras las cosas sean así, no quiero que usted padezca por mi causa, a pesar de que usted sea rico. Por este motivo le presento las condiciones de esta manera para que la empresa sea posible. He ganado ya un público pequeño para mis escritos, y cuando éste se vuelva más numeroso, mi libro tendrá más ediciones, aunque ya no esté yo para verlas.

La última revisión del segundo tomo estará lista para impresión en un mes. Mientras imprime el segundo tomo, me gustaría hacer unas pequeñas mejoras al primero: en especial, al apartado de la «Crítica a la filosofía kantiana». Usted verá que son de interés, y no ocuparán más que un pliego.

Espera su respuesta con el mayor de los respetos

$\mathrm{Su}$ fiel

Arthur Schopenhauer. Frankfurt, 7 de mayo de 1843.

\section{[A F. A. Brockhaus]}

Mi señor

Me ha comunicado en su venerable misiva una respuesta negativa a mi petición, la cual me resulta tan inesperada como descorazonadora. A pesar de ello, debo rechazar los consejos bienintencionados que me hace. Estoy dispuesto a darle un regalo al público, un regalo de mucho valor: ¡pero pagar por dar ese regalo no lo haré ahora ni nunca! ¡Es como si alguien a quien le fuera a comunicar por escrito una muy importante noticia quisiera que yo franqueara la carta! El evidente deterioro de nuestra época ha llegado a tal extremo que las estupideces de Hegel son reeditadas una y 
otra vez, y las huecas sandeces filosóficas escritas por la gente más ordinaria son adquiridas por el público y se agotan en todas las ferias de libros, mientras que mi obra, el trabajo de toda una vida, no quiere ser financiada por mi editor; en todo caso, será mejor que se quede guardada y aparezca de manera póstuma, cuando lleguen las generaciones que sepan recibir con alegría cada una de mis líneas: esto no tardará mucho.

Sin embargo, creo que éste no es el estado definitivo de las cosas: quisiera agotar todos los medios para hacer accesible al mundo este trabajo que he completado con tanto amor y dedicación. En primer lugar, le propongo imprimir el segundo tomo sin reimprimir el primero y sin que se me paguen honorarios - a pesar de que esto vaya contra mi propio interés. Usted no debe dudar de que aquellos que tienen el primer tomo querrán tener el segundo; dichas ventas cubrirán los gastos de la impresión. Rumores sobre el valor de mi libro llegarán a los oídos de la gente con toda seguridad. Este segundo tomo, la suma de todos los pensamientos que he escrito en los últimos 24 años - el cual se encuentra dividido en 54 apartados, independientes entre sí- trata distintos temas filosóficos, no con la jerga universitaria, sino de una manera extremadamente clara, viva e intuitiva que raya en lo popular, y que es además agradable y fácil de leer: es por ello que el primer tomo - cuyo contenido supone los conocimientos básicos de mi filosofía- despertará también interés, y con suerte conducirá a una segunda edición. Si usted estuviese aquí, le daría a leer (aquí mismo en mi residencia, pues comprenderá que no dejo que nadie tenga una copia del manuscrito) las 36 páginas que provisionalmente conforman el capítulo de la «Metafísica del amor sexual», donde estudio los fundamentos más profundos de esta pasión con un lenguaje que cuida los detalles más precisos. Apuesto a que después de esto usted cambiaría de parecer.

Si usted decide no aceptar esta segunda propuesta, entonces deberé buscar un editor por todos los medios posibles, el cual, sin lugar a dudas, me preguntará por qué usted no aceptó publicar el segundo tomo. Esto hace las cosas más difíciles. Si no se tratase de un segundo tomo, no me faltarían editores que me publicaran sin pagarme honorarios. Si en su medio no existe alguien impar- 
cial y con amplio panorama que pueda convencerlo del valor de mis ideas, le recomiendo entonces que vea cómo habla Jean Paul en su Estética de este libro mío que tan mal negocio ha resultado para usted; o lo que dice Rosenkranz en su «Historia de la filosofía kantiana», en el doceavo tomo de su edición de las obras de Kant, donde me coloca junto a Fichte y Herbart en el lugar de honor que me corresponde como filósofo de primer rango; o en la revista «Piloto» de mayo de 1841, donde aparece un ensayo titulado «El tribunal más joven de la filosofía hegeliana», escrito por alguien que no conozco, y quien afirma que, con todo merecimiento, soy el filósofo más grande de esta época. En vista de estas cosas, ¿no cree que soy un hombre cuyos costos de impresión merecen ser sufragados? Sé muy bien que el valor de los escritos va de la mano con las ventas. Al gran David Hume le pasó en un principio lo mismo que a mí: su Historia de Inglaterra, que aún después de 80 años vuelve a ser reeditada cada año y es traducida cada vez a más idiomas, sólo pudo vender 45 tomos el primer año, tal y como él mismo lo confiesa. En la «Revista de tertulias literarias» de usted, leí este invierno que Göschen se quejaba de las bajas ventas de la Ifigenia y del Egmont de Goethe, iy afirmaba que las ventas del Wilhelm Meister eran mucho peores! Por otra parte, el semanario «Locomotive» vende 8000 ejemplares diarios: ¡es de no creerse!

No crea de ninguna manera que le reclamo hablar desde su propia posición, ya que yo lo hago desde la mía. Sé que uno no puede negociar con cosas de la posteridad. Sólo le pido que medite sobre mi segunda propuesta y los motivos que le señalo, y de ser el caso en que usted la vuelva a rechazar, le pido que me diga cuántos ejemplares conserva de la primera edición. ¿En verdad no quiere tener los derechos completos de una segunda edición?

Con el mayor respeto, espera de usted su favorable respuesta Su fiel

Arthur Schopenhauer. Frankfurt, 17 de mayo de 1843. 


\section{[A su linotipista]}

¡Mi querido linotipista! Nosotros somos como el cuerpo y el alma; tal como estos dos, nosotros debemos cuidarnos el uno al otro, de suerte que hagamos un trabajo que sea del agrado del señor Brockhaus. Yo ya he hecho lo que me correspondía, y siempre, en cada línea, en cada palabra, e incluso en cada letra, he pensado en usted, en caso de que usted mismo quiera leer la obra. Ahora le toca hacer lo suyo. Mi manuscrito no tiene una letra grácil, sino grande y clara. Las constantes revisiones y correcciones hicieron que modificara varias cosas e intercalara algunas otras. Sin embargo, todas estas intercalaciones están indicadas de manera precisa, con el propósito de que usted no se equivoque, en el supuesto, claro, de que usted las estudie con atención y compruebe que todo esté en orden al confrontar las marcas y las correcciones. Respete mi ortografía y mi puntuación; no crea que usted comprende esto mejor, pues yo soy el alma y usted es el cuerpo. Al final de cada línea, le he marcado las añadiduras con una pequeña señal, ¡así que no crea que se tratan de taches! Lo que he escrito con letras latinas entre corchetes son indicaciones para usted. Cuando vea una palabra tachoneada, fíjese si no hay una palabra anotada que la substituya; y, sobre todo, no piense nunca que lo que le señalo es un descuido de mi parte. En muchas ocasiones, las palabras que he creído que pueden ser un tanto extrañas para usted, las he repetido con letras latinas en corchetes entre las líneas. Tenga en cuenta que todas estas correcciones que ahora le son fatigosas lo serían aún más si es que me pusiera a corregir el estilo y a hacer mejoras con las pruebas de imprenta.

Las vocales dobles y las palabras cuya «h» no es muda las escribo a la antigua usanza. No coloco comas antes de los «porque», sino puntos. Escribo varias palabras de acuerdo a como se escribían antes; uso diéresis en lugar de diptongos. Hágale saber estas recomendaciones al corrector. Quiero que cada libro y cada capítulo estén señalados del lado izquierdo, y que, inmediatamente, se señale el título del capítulo. Por ejemplo, en el lado izquierdo deberá decir «IV, 43», mientras que en el lado derecho estará el título («Carácter hereditario de las facultades»), y así deberán de estar todos. 
Sólo el primer libro se divide en dos mitades. No es necesario dividirlos con una página intermedia; con el simple título bastará. Arthur Schopenhauer. 7 de septiembre de 1843. 